\title{
Strategies for cancer prevention: the role of diet
}

\author{
J. A. Milner \\ Nutrition Department, The Pennsylvania State University and Nutritional Science Research Group, Division of Cancer \\ Prevention, National Cancer Institute, 6116 Executive Boulevard Suite 703, Rockville, MD 20892, USA
}

\begin{abstract}
Linkages between diet habits and cancer risk have surfaced from a multitude of epidemiological and preclinical studies. Collectively these studies provide rather compelling evidence that dietary components modify the incidence and biological behavior of tumors. While the risk of breast, prostate, colon, lung and liver cancers are frequently associated with dietary patterns, inconsistencies are not uncommon. These inconsistencies likely reflect the multi-factorial and complex nature of cancer and the specificity that individual dietary constituents have in modifying cancer related genetic pathways. The complexity of defining the role of diet is underscored by the numerous and diverse essential and non-essential components that may alter one or more phases of the cancer process. The explosive increase in the recognition of genes and pathways for regulating cell growth and development, and evaluating the response to hormones and other chemicals synthesized by the body, offers exciting opportunities for unraveling the molecular targets by which dietary components influence cancer prevention. It is recognized that all cells have unique 'signatures' that are characterized by active and inactive genes and cellular products. It is certainly plausible that bridging knowledge about these unique cellular characteristics with the molecular targets for nutrients can be used to assist in optimizing nutrition and minimizing cancer risk.
\end{abstract}

Diet: Cancer: Polymorphism: Genes: Phytochemicals

\section{Introduction}

Belief in the medicinal powers of foods is not a new concept but has been passed down for generations. Hippocrates is frequently quoted as saying around 2500 years ago 'Let food be thy medicine and medicine be thy food.' Today claims about the ability of foods and food components to reduce disease risks or enhance the quality of life continue to captivate consumers. Undeniably a strategy that utilizes foods and their components to optimize nutrition to achieve genetic potential, improve physical and cognitive performance and reduce the risk of some diseases, including cancer, is highly commendable and appropriate for reducing health care cost and improving the quality of life. While defining the most effective diet for an individual will not be easy there is mounting scientific evidence to believe that a dietary approach is feasible.

Numerous observational studies point to the likelihood that diet is a significant determinant of cancer risk Weisburger, 2000; Van Duyn \& Pivonka, 2000; Wargovich, 1999). Much of this evidence indicates that the greatest protection coincides with greater fruit, vegetable and grain consumption. While it has been almost three decades since dietary habits were proposed to account for $60 \%$ of cancers in women and more than $40 \%$ in men (Wydner \& Gori, 1977), the foods and/or components that provide the greatest protection remains largely obscure. Nevertheless, intriguing preclinical and epidemiological studies provide evidence linking various nutrients - defined here as any substances ingested in the diet that have physiological effects - and cancer. The past decade has witnessed the publication of several articles that question the role of diet in the cancer process (Smith-Warner et al. 2001; Schatzkin et al. 2000) and thus have raised concerns about what is and is not physiologically important and the circumstances that may dictate the overall response (Martinez \& Giovannucci, 1997; Milner, 2000a,b, Whiteley \& Klurfeld, 2000). Increasingly genetics are being recognized to have an intimate involvement in directing the cancer process and thus a likely modifier of the response to diet. A greater focus on research to address how nutrients influence genetic pathways associated with cancer and visa versa offers hope to untangling this conundrum.

Abbreviations: ACF, aberrant crypt foci; CGAP, Cancer Genome Anatomy Project.

Note: For the definition of the terms inulin and oligofructose please refer to the introductory paper (p. S139) and its footnote.

Corresponding author: Dr J. A. Milner, tel +1 301496 0118, fax +1 301480 3925, email milnerj@mail.nih.gov 


\section{Numerous dietary modifiers and biological responses}

To date more than 500 dietary compounds have been identified as potential modifiers of cancer. Both essential and non-essential-allelochemicals in plants, as well as zoochemicals occurring in animal products, may be physiologically important modifiers. Compounds encompassing such diverse categories as carotenoids, dithiolthiones, flavonoids, glucosinolates, isothiocyanates, allyl sulfhydryls and fermentable fibers have been found to influence experimentally induced cancers. Numerous reviews extolling the merits (and possible risk) of these and other bioactive food components have surfaced in recent years (Potter, 1997; Craig, 1997; Diplock et al. 1998; Milner, 2000a; Gill \& Cross, 2000; Abdulla \& Gruber, 2000). Increasingly nutrients are being recognized to influence genetic and epigenetic processes that determine cellular metabolism, differentiation and apoptosis (Bradlow et al. 1999; Lipkin et al. 1999; Knowles \& Milner, 2000; Zhu \& Williams, 1998). While the study of 'Nutritional Genomics' is in its infancy it is beginning to reveal that nutrient excesses and deficiencies can bring about a host of genomic and proteonomic changes. Regardless of whether the molecular target is at the transcription, translation or post-translational level the net result is an up- or down-regulation of specific gene products.

Complementary and overlapping mechanisms appear to account for the response to bioactive food components. These biological responses encompass such diverse functions as serving as an antioxidant, promoting the activity of detoxification enzymes, blocking carcinogen formation (such as with nitrosamines), shifting hormonal homeostasis, retarding cell division, and inducting apoptosis. Since more than one of these responses may occur simultaneously it is difficult to determine which is most important in dictating the change in cancer risk and/or tumor behavior. Table 1 lists some of the likely mechanisms by which dietary components may suppress the cancer process. It is clear that some nutrients can bring about the

Table 1. Mechanisms by which nutrients may suppress the cancer process

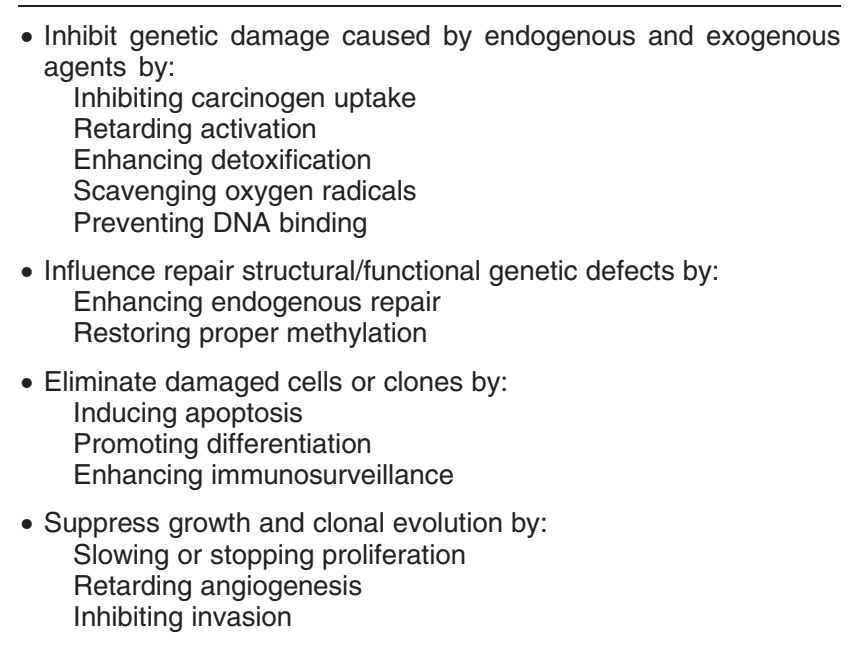

opposite effects and thereby enhance carcinogenesis. The ability of several nutrients to influence the same biological processes raises issues about possible synergy, as well as antagonistic interactions, among dietary components.

A host of factors can contribute to DNA instability and ultimately to tumor development. Endogenous agents, including methylating species and reactive oxygen species arising during normal cellular respiration, are recognized to lead to DNA damage. Some nutrients such as unsaturated fatty acids and iron may influence this process by promoting the formation of the damaging agents, while other components such as some flavonoids and folate may function to enhance endogenous repair mechanisms. Support for this contention comes from recent observation that an aqueous fraction of Fushimi sweet pepper increases repair against UV-induced cyclobutane pyrimidine dimers in human fibroblasts (Nakamura et al. 2000). Other data point to the essentiality of folate in maintaining normal DNA synthesis and repair (Duthie et al. 2000). Some dietary components may also retard repair as has been suggested following alcohol exposure (Asami et al. 2000). The importance of understanding how nutrients influence repair processes resides in determining the direction the cell takes in modifying cell cycle checkpoints and/ or apoptosis. Unquestionably, DNA replication is central to cell growth, development, and generation of tissues and organs. Recent advances in understanding replication machinery have revealed striking conservation of components involved in the DNA replication processes, from yeast to humans, thus raising the possibility of using various models to test the site of action of nutrients.

Cell homeostasis is regulated by a delicate balance among proliferation, growth arrest, differentiation and apoptosis (programmed cell death). While vitamin A has been repeatedly linked to differentiation, other nutrients such as vitamin D and lignan can also be involved (Ward et al. 2000; Basak et al. 2001; Gray et al. 2001). Dysregulation of apoptosis is frequently accompanied with the pathogenesis arising from a wide array of conditions including cancer, neurodegeneration, autoimmunity, heart disease and others. Diverse nutrients including plant sterols, selenium and even butyrate arising from fermentable fibers may promote apoptosis (Awad \& Fink, 2000; Schrauzer, 2000; Chapkin et al. 2000). One of the major issues to be addressed is if typical intakes of these dietary components are sufficient to bring about these effects.

Evidence already exists that the transcriptional silencing of selected genes by DNA methylation plays a crucial role in a number of diseased states including cancer (Ahuja \& Issa, 2000). Evidence with yeast indicates that caloric restriction can lead to the silencing of a variety of genes (Guarente \& Kenyon, 2000). Caloric restriction has repeatedly been found to retard chemically induced and spontaneous tumors in model systems (Kritchevsky, 1999). Genes involving cell cycle regulation, DNA repair, angiogenesis, and apoptosis are all inactivated by the hypermethylation of their respective $5^{\prime} \mathrm{CpG}$ islands. Key regulatory genes including E-cadherin, pi-class glutathione S-transferase, the tumor suppressors cyclindependent kinases (CDKN2) and phosphatase gene (PTEN), and insulin-like growth factor (IGF-II) targeted 
histone acetylation/deacetylation are influenced by DNA hypermethylation. While folate intake is recognized to influence DNA methylation patterns other nutrients such as selenium can also have an impact (Duthie, 1999; Davis et al. 2000). Restoring proper methylation may represent a fundamental process by which selected nutrients are able to influence the cancer process.

In addition to influencing immunocompetence, the availability of nutrients can influence the invasiveness of tumors and retard angiogenesis. The importance of this observation is that angiogenesis is a prerequisite for tumor growth and metastasis. Vascular endothelial cell proliferation, migration, and capillary formation are all known to be stimulated by several angiogenic growth factors as well as eicosanoids synthesized from $n-6$ fatty acids (Rose \& Connolly, 2000). Clinical studies provide evidence that angiogenesis in solid tumors relates to a poor prognosis. Lipoxygenase and cyclo-oxygenase products of $n-6$ fatty acid metabolism are angiogenic in in vitro assays. The activity of both of these enzymes can be suppressed by the consumption of resveratrol found in grapes, or n-3 fatty acids occurring in fish (Subbaramaiah et al. 1999; Pinto et al. 1999; Rose \& Connolly, 2000). Likewise, genistein found in soybean products and selenium found in fish and grains have been reported to influence angiogenesis by still to be defined mechanisms (Jiang et al. 1999; Zhou et al. 1999).

Collectively, overwhelming evidence demonstrates that a variety of nutrients can influence a number of key intracellular targets. Determining which one of these targets is most important in altering tumor growth will not be a simple task. Likewise, unraveling the multitude of interactions among nutrients with these key events makes the challenge even more daunting. Finally inter-individual differences probably reflecting genetic polymorphisms can mask the response to a nutrient and thereby complicate this undertaking to an even greater extent. Nevertheless, deciphering the role of diet is fundamental to optimizing health. With this information the reason for the inconsistencies in the nutrition and cancer literature will be revealed and meaningful and tailored strategies can be developed to assist individuals in minimizing their cancer risk.

\section{Dynamics between biomarkers and long-term intervention}

Scientifically sound intervention studies must be viewed as the cornerstone for establishing nutrition guidance. Unfortunately, the number of long-term intervention studies that will be needed to define nutrient interactions will surely be impractical in terms of speed of discovery and overall cost. Alternative procedures that utilize sensitive and reliable biomarkers will need to be developed to assist in determining who might benefit most, who might be placed at risk and the minimum quality of the food and/or component needed to bring about the intended response. Predictors similar to those used by environmental toxicologists (Sakai, 2000; Suk \& Collman, 1998) will be needed to evaluate the benefits/risk accompanying exaggerated use of functional foods and their components. Thus biomarkers are needed that can assess: (i) the active agent(s) capable of modifying target tissues (intake/exposure Biomarker), (ii) specific and reliable biological responses which evaluate directly or indirectly disease risk or health maintenance (effect biomarker), and (iii) factors modifying the response such as genetic and the environment (susceptibility biomarker) (Milner, 2000b). Clearly, to assess whether a food or its constituent has a physiological effect it is imperative that stringent experimental design characteristics are followed. Several factors including appropriateness of controls, randomization of subjects, blinding, statistical power of study, presence of bias, attrition rates, recognition and control of confounding factors (e.g. weight change or nutrition status) and appropriateness of statistical tests and comparisons as addressed in a Guidance document published in the Federal Register (1999). Each of these factors must become the mainstay for all investigations. Many of these same factors must also be considered in the conduct of preclinical investigations. Whatever biomarkers are established it is clear that they must be readily accessible, easily and reliably assayed, differentially expressed in normal and diseased conditions, directly associated with disease progression, modifiable and most important 'predictive' (Fig. 1). Similar to the USDA pyramid that is used for dietary guidance it is likely that the early predicative biomarkers will not be at the apex because of the lateness of the observation but be focused at the base where it will be more specific and timely. Thus, the future of biomarkers likely resides in the enhanced used of molecular technologies to help decode who will and will not benefit from intervention strategies, and as important, who might be placed at harm because of the approach taken.

\section{Moving beyond observational studies}

The future of nutrition and cancer research resides in the ability to move beyond observational studies to a molecular

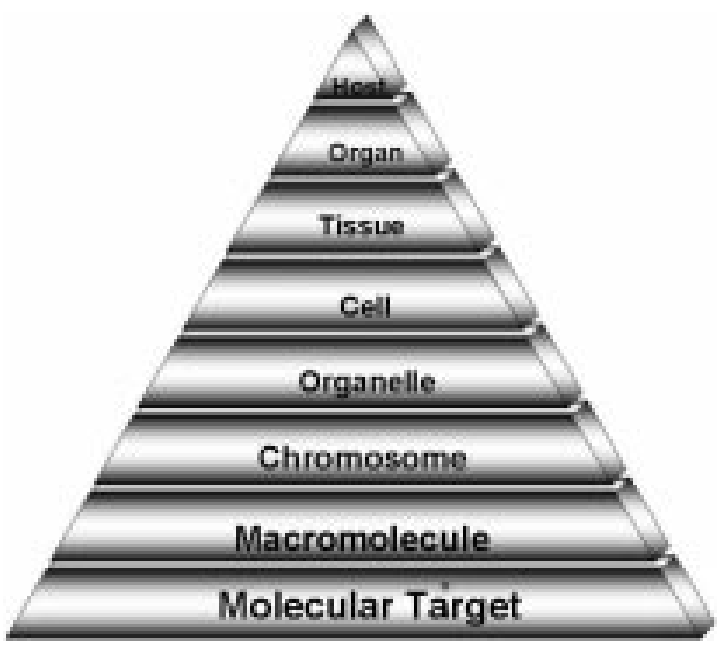

Fig. 1. Molecular targets for selenium. Selenium is reported to influence a number of proteins involved in oxidative stress, drug detoxification, cell division and apoptosis. Future research needs to determine which of these changes in most important in bringing about a change in the incidence or behavior of tumors. 
approach that will allow for tailored recommendations (Greenwald et al. 2001). The study of nutritional genomics has the potential to identify definitively which components in foods bring about either cancer-inhibitory or cancerenhancing effects and to clarify their relevant mechanisms-of-action; this should lead to the identification of molecular targets that can be manipulated for cancer prevention. About 26000 to 38000 genes are found in the first draft of the human genome, which is about double that found in the fruit fly and worm (Paabo, 2001). A website (gov/ncicgap), part of the recently launched Cancer Genome Anatomy Project (CGAP) that was developed jointly by the National Cancer Institute (NCI) and National Library of Medicine offers scientists a powerful new tool to study diet and cancer interrelationships. Scientists can literally click on the CGAP website and submit queries about genes expressed during the development of cancer. In response, the CGAP database will sort through its gene index in seconds and provide a list of genes relevant to the query; data that a few years ago might have taken years or even lifetimes to compile. Genomic data for human and mouse, include expressed sequence tags (EST), gene expression patterns, single nuclear polymorphisms (SNP), cluster assemblies, and cytogenetic information. For example while there are many genes that are expressed in colon tissue about 900 have not been found to be expressed in other tissues. In addition to genetic information this web site contains informatics tools to query and analyze the data and information on methods and resources for reagents developed by the project. All CGAP resources - including cDNA libraries, clones, and sequence data - are publicly accessible to scientists.

\section{Nutrients have molecular targets}

A fundamental action of a nutrient is to serve as a regulator of gene expression and/or a modulator of a gene product. Thus nutrients have specific sites of action which can best be described as molecular targets. These molecular targets may be individual genes, molecules that either result from gene expression or are otherwise affected by gene expression, or any other molecular events that are relevant to the process of carcinogenesis. The increasing recognition of the diversity of molecular targets demonstrates the complexity and breadth of actions that nutrients can have in increasing or decreasing cancer risk.

Some of the most compelling evidence that diet can influence the cancer process comes from the intervention study by Clark et al. (1996) with selenium yeast as a supplement. Most of the current evidence suggests that while supplemental selenium may retard cancer risk, classical selenium deficiency per se may not be prerequisite for increased risk. Support for this contention is underpinned by a wealth of studies with cancers arising experimentally at various sites (Ganther, 1999; Ip, 2000; Liu \& Milner, 1992; Redman et al. 1998; Schrauzer, 2000; Sinha et al. 1996; Ip et al. 2000; Davis et al. 2000; Zhu et al. 2000). Although much of the attention given to selenium has been about its antioxidant activity, this trace element is known to bring about a diverse set of biological effects including a suppression in cell proliferation, enhancement of immunocompetence, blocking of carcinogen metabolism, and the induction of apoptosis (Fig. 2). By identifying which one of the events is most important in altering the phenotypic characteristics of the tumor it should be possible to identify who will and might not benefit from exaggerated intakes of this trace element. The characterization of the specific molecular target(s) for this and other nutrients represents a major hurdle for the science of nutrition. Nevertheless, it is fundamental to truly understanding the involvement of nutrients in cancer prevention as well as in other health anomalies.

Another nutrient with apparent significance in the cancer process is folate (folic acid). Its essential role in de novo biosynthesis of purines and pyrimidines, and thus DNA replication and cell division, and for the synthesis of $S$-adenosylmethionine (SAM), a methyl donor for more than 100 biochemical reactions including methylation of DNA, places it in a unique position relative to DNA stability (Kim et al. 1997). These biosynthetic pathways, each of which is important to DNA metabolism, appear to compete when the dietary methyl supply is inadequate, as in folate deficiency, possibly resulting in altered DNA methylation (an epigenetic event), disruption of DNA integrity, and disruption of DNA repair and, consequently, increased risk for carcinogenesis (Choi \& Mason, 2000; Mason \& Levesque, 1996; Rampersaud et al. 2000). Some of the most compelling evidence linking folate deficiency and cancer comes from colorectal risk; although evidence does exist that risk of lung, uterine cervix, esophagus, stomach, pancreas, liver, breast, and colon/rectum may also be associated (Mason \& Levesque, 1996). Hypomethylation and DNA strand breaks arising from folate inadequacy may actually promote the incorporation of viruses such as human papilloma virus (HPV) into human DNA (Choi \& Mason, 2000; Piyathilake et al. 2000). In humans, folate administration significantly reversed hypomethylation in patients with chronic atrophic gastritis (Fang et al. 1997) and colorectal cancer (Cravo et al. 1994).

A number of nonessential phytonutrients have also been found to impact the cancer process. Diethiolethione represents one class of nutrients that has been reported to influence a variety of molecular targets associated with

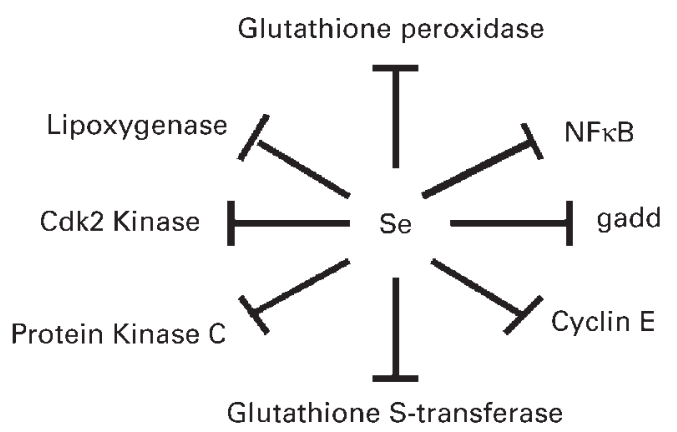

Fig. 2. Intermediate endpoints for evaluating the impact of diet on cancer prevention. Special thanks to Dr E. Hawk, Chief Gastrointestinal and other Cancer Research Group, Division of Cancer Prevention, National Cancer Institute, for his insights into the development of this figure. 
cancer (Kensler et al. 2000). One of the major mechanisms of protection against carcinogenesis, mutagenesis, and other forms of toxicity mediated by carcinogens is the induction of enzymes involved in their metabolism, particularly phase-2 enzymes such as glutathione S-transferases, UDP-glucuronosyl transferases, and quinone reductases. Animal studies indicate that induction of phase- 2 enzymes is a sufficient condition for obtaining chemoprevention and can be achieved by administering any of a diverse array of naturally-occurring and synthetic chemopreventive agents. Exposure of rodents to 1,2-dithiole-3thiones triggers nuclear accumulation of the transcription factor Nrf2 and its enhanced binding to the antioxidant response element, leading to transcriptional activation of a score of genes involved in carcinogen detoxification and attenuation of oxidative stress. Nrf2-deficient mice fail to induce many of these genes in response to oltipraz, a synthetic dithiolthione (Ramos-Gomez et al. 2001). Similar studies using transgenic or knock-out animals are needed to define the precise site of action of not only isothiocyanates but a host of other nutrients.

The hypothesis that fiber might decrease cancer risk, especially in the colon, has been a topic of discussion for well over a quarter of a century. Several mechanisms have been proposed to account for the epidemiological findings and the ability of selected fiber to alter risk in animal models (Table 2). Unfortunately recent intervention studies raise real issues about what role that fiber has in cancer prevention, if any (Schatzkin et al. 2000). Schatzkin et al. (2000) reported that a 4-year study that increased ingestion of fruits, vegetable and fiber was not accompanied by a change in the risk of recurrent of polyps. It is conceivable that for fiber to have an impact that it has to be introduced earlier in the cancer process and thus examining individuals who are highly susceptible to the reoccurrence of polyps may not be the most appropriate target group. Likewise, this study raises the possibility that not all fiber sources are equivalent in their ability to alter cancer risk. This is not a new concept since it is becoming increasingly apparent that dietary fiber is not a single entity. While soluble fibers have been reported to reduce cholesterol concentrations it is clear that not everyone responds identically again raising the possibility that selected genes may be instrumental in the response that occurs (Brown et al. 1999). What genetic variation might account for this variation in response is a key question that remains not only with regard to cholesterol but also for other health related conditions.

Inulin and oligofructose represent intriguing dietary fermentable fibers that may have an impact on cancer

Table 2. Proposed mechanism by which fiber rich foods may retard colon cancer

Increase stool bulk

Decrease transit time

Binds to bile acids and salts

Ferments to volatile fatty acids

Binds to carcinogens

Alters colonic microflora risk (Roberfroid, 1993). Inulin and oligofructose are fructans with a degree of polymerization of 2-60 and 2-20, respectively. Due to the structural conformation they are resistant to hydrolysis by human alimentary enzymes and therefore are fermented almost exclusively by colonic bifidobacteria and bacteroides. This fermentation increases fecal bacterial biomass, decreases ceco-colonic $\mathrm{pH}$, and produces a large amount of fermentation products among which are the short-chain fatty acids. It is unclear if its recognized ability to influence the intestinal content of biofidobacteria (Kruse et al. 1999) accounts for part of its ability to suppress chemically induced colon cancer and depress the frequency of colonic aberrant crypt foci (Reddy, 1999). Interestingly inulin has also been reported to retard the incidence of experimentally induced mammary tissue and suppress the growth of transplantable tumors (Taper \& Roberfroid, 1999). Even though fermentation to short-chain fatty acids is a mechanistically attractive hypothesis to explain why fiber modulates cytokinetics, data do not consistently support short-chain fatty acids as biological intermediates in risk of colon cancer. Additional markers of apoptosis, differentiation, and cell-cell communication need to be examined to more accurately define the relation of inulin and among fiber sources as modifiers of cytokinetics and ultimately colon cancer risk.

The monitoring of aberrant crypt foci (ACF) hold promise as a sensitive biomarker, both as marker of risk and as intermediate end-points for chemoprevention trials (Baron, 2001). Reddy et al. (1997) reported that when rats were fed a relatively large amount of inulin (10\% diet) that the number of ACF was substantially reduced in azoxymethane treated rats. Subsequent studies by Rao et al. (1998) reported that inulin had no significant effect on total ACF, but did reduce the number of $\mathrm{ACF} / \mathrm{cm} 2$ $(P<0.05)$ in azoxymethane treated rats. Oligofructose (from sucrose) dramatically reduced the incidence of colon tumors in C57BL/6J-Min/+ mice, which are heterozygous for a non-sense mutation in the Apc gene, thus being a model for both familial adenomatous polyposis and sporadic colon cancers (Pierre et al. 1997). Interestingly, neither starch-free wheat bran nor resistant starch modified the number of tumors in this model. Such information supports the contention that not all fibers are equivalent in their ability to alter cancer risk.

\section{Genetic polymorphisms and dietary variability}

Increasingly, genetic polymorphisms are thought to have a role in the ability of individuals to withstand exposure to exogenous carcinogens or to inhibit initiation, promotion, or proliferation in carcinogenesis. Unfortunately, while this area is beginning to receive greater attention it remains unclear how polymorphisms are related to the impact of diet on the cancer process (Vineis, 1999). Nevertheless, it is certainly plausible that polymorphic differences have been a contributing factor in the inconsistencies surrounding dietary components and health (Cotton et al. 2000). Evidence already exists that the prevalence of polymorphisms is an important variable that can influence the outcome of otherwise solidly-designed trials. For 
example, in a random sample of participants in the AlphaTocopherol, Beta-Carotene Cancer Prevention Study (ATBC Study), there was a low prevalence of polymorphisms in genes coding for activation (phase I) enzymes CYP1A1 (0.07) and CYP2E1 (0.02) and a high prevalence in genes coding for detoxification (phase II) enzymes GSTM1 (0.40) and NQO1 (0.20) (Woodson et al. 1999). Interestingly, seven of ten members of this sample carried the VDR-Taq1 polymorphism (t) associated with lower risk for prostate cancer, which may account in part for lower cancer rates in Finland when compared with the USA (Woodson et al. 1999). Further, in a nested case-control study within the ATBC Study, glutathione peroxidase 1 (hGPX1), a selenium-dependent enzyme involved in detoxification of hydrogen peroxide, was found to have a polymorphism exhibiting a proline to leucine replacement at codon 198. This polymorphism conferred a relative risk for lung cancer risk of 1.8 for heterozygotes and 2.3 for homozygous variants compared with homozygote wild types (Ratnasinghe et al. 2000).

A number of polymorphisms of the Vitamin D receptor (VDR) gene have been identified; common polymorphisms include BsmI, TaqI in intron 8 and exon 9, and a poly-A site in the $3^{\prime}$ end of the gene. In a recent population study, BsmI B and short poly-A polymorphisms in the $3^{\prime}$ end of the $V D R$ gene were associated with increased breast cancer risk (Ingles et al. 2000). BsmI B polymorphisms ( $\mathrm{BB}$ and $\mathrm{Bb}$ ) also have been associated with decreased risk of prostate cancer and benign prostatic hyperplasia when compared with BsmI bb genotypes among Japanese men (Habuchi et al. 2000).

Several common genetic polymorphisms appear to modulate cancer risk through their influence on folate metabolism, including two polymorphisms of the methylenetetrahydrofolate reductase $(M T H F R)$ gene. Epidemiological studies have reported that, when folate intake was adequate, colorectal cancer risk was reduced $(50 \%)$ in individuals with the MTHFR 677TT genotype compared with the MTHFR 677CC genotype (Chen et al. 1999; Slattery et al. 1999) and risk of adult acute lymphocytic leukemia (ALL) was reduced by $77 \%$ (Skibola et al. 1999). Genetic polymorphism became less of an issue when dietary folate intake is low (Ma et al. 1997).

\section{The future}

Research in nutrition and cancer prevention in this new millenium must give top priority to studies that will aid in understanding the basic molecular basis by which nutrients influence the cancer process. A well-coordinated, multidisciplinary effort among scientists - including nutritional scientists, molecular biologists, geneticists, statisticians, and clinical cancer researchers - may be needed to advance this molecular approach to nutrition-related cancer research. Many research questions and issues will need to be addressed for this approach to become a reality. For example, can the impact of a nutrient be determined by one molecular target or do multiple sites of action account for the response? Do interactions among nutrients determine the response and ultimately cancer risk? Again some of these interactions may be beneficial while others the opposite. It will be necessary to determine if age and gender are significant determinants of the response to a given nutrient. Key to moving this science forward will be the identification and validation of biomarkers that can be used to assess intake, effect and susceptibility. A goal must be to determine if nutrient-modulated biomarkers can serve as surrogate endpoint biomarkers and what tissue or fluid measurements can be used to predict occurrences at tissue sites. Undeniably it will be critical to determine if currently used study designs and analytical techniques are adequate to move the molecular-based nutrition and cancer research arena forward.

The development and implementation of a successful multidisciplinary effort that emphasizes a molecular approach to nutrition-related cancer research will take motivation, dedication, and specialized training. While the challenges to researchers will be enormous, the potential rewards in terms of reducing cancer morbidity and mortality can conceivably be enormous.

\section{References}

Abdulla M \& Gruber P (2000) Role of diet modification in cancer prevention. Biofactors 12, 45-51.

Ahuja N \& Issa JP (2000) Aging, methylation and cancer. Histology and Histopathology 15, 835-842.

Asami S, Hirano T, Yamaguchi R, Tsurudome Y, Itoh H \& Kasai $\mathrm{H}$ (2000) Increase in 8-hydroxyguanine and its repair activity in the esophagi of rats given long-term ethanol and nutritiondeficient diet. Japanese Journal of Cancer Research 91, 973-978.

Awad AB \& Fink CS (2000) Phytosterols as anticancer dietary components: evidence and mechanism of action. Journal of Nutrition 130, 2127-2130.

Baron JA (2001) Intermediate effect markers for colorectal cancer. IARC Scientific Publications 154, 113-129.

Basak R, Bhattacharya R \& Chatterjee M (2001) 1-alpha,25dihydroxyvitamin $\mathrm{D}(3)$ inhibits rat liver ultrastructural changes in diethylnitrosamine-initiated and phenobarbital promoted rat hepatocarcinogenesis. Journal of Cellular Biochemistry 81, 357-367.

Bradlow HL, Telang NT, Sepkovic DW \& Osborne MP (1999) Phytochemicals as modulators of cancer risk. Advances in Experimental Medicine and Biology 472, 207-221.

Brown L, Rosner B, Willett WW \& Sacks FM (1999) Cholesterol-lowering effects of dietary fiber: a meta-analysis. American Journal of Clinical Nutrition 69, 30-42.

Chapkin RS, Fan Y \& Lupton JR (2000) Effect of diet on colonicprogrammed cell death: molecular mechanism of action. Toxicology Letters 112-113, 411-414.

Chen J, Giovannucci EL \& Hunter DJ (1999) MTHFR polymorphism, methyl-replete diets and the risk of colorectal carcinoma and adenoma among U.S. men and women: an example of gene-environment interactions in colorectal tumorigenesis. Journal of Nutrition 129, 560S-564S.

Choi SW \& Mason JB (2000) Folate and carcinogenesis: an integrated scheme. Journal of Nutrition 130, 129-132.

Clark LC, Combs GF Jr, Turnbull BW, Slate EH, Chalker DK, Chow J, Davis LS, Glover RA, Graham GF, Gross EG, Krongrad A, Lesher JL Jr, Park HK, Sanders BB Jr, Smith CL \& Taylor JR (1996) Effects of selenium supplementation for cancer prevention in patients with carcinoma of the skin. A randomized controlled trial. Nutritional Prevention of 
Cancer Study Group. Journal American Medical Association 276, 1957-1963.

Cotton SC, Sharp L, Little J \& Brockton N (2000) Glutathione S-transferase polymorphisms and colorectal cancer: a HuGE review. American Journal of Epidemiology 151, 7-32.

Craig WJ (1997) Phytochemicals: guardians of our health. Journal of the American Dietetic Association 97, S199-S204.

Cravo M, Fidalgo P, Pereira AD, Gouveia-Oliveira A, Chaves P, Selhub J, Mason JB, Mira FC \& Leitao CN (1994) DNA methylation as an intermediate biomarker in colorectal cancer: modulation by folic acid supplementation. European Journal of Cancer Prevention 3, 473-479.

Davis CD, Uthus EO \& Finley JW (2000) Dietary selenium and arsenic affect DNA methylation in vitro in Caco-2 cells and in vivo in rat liver and colon. Journal of Nutrition 130, 2903-2909.

Diplock AT, Charleux JL, Crozier-Willi G, Kok FJ, Rice-Evans C, Roberfroid M, Stahl W \& Vina-Ribes J (1998) Functional food science and defence against reactive oxidative species. British Journal of Nutrition 80, S77-S112.

Duthie SJ (1999) Folic acid deficiency and cancer: mechanisms of DNA instability. British Medical Bulletin 55, 78-92.

Duthie SJ, Narayanan S, Blum S, Pirie L \& Brand GM (2000) Folate deficiency in vitro induces uracil misincorporation and DNA hypomethylation and inhibits DNA excision repair in immortalized normal human colon epithelial cells. Nutrition and Cancer 37, 45-51.

Fang JY, Xiao SD, Zhu SS, Yuan JM, Qiu DK \& Jiang SJ (1997) Relationship of plasma folic acid and status of DNA methylation in human gastric cancer. Journal of Gastroenterology 32, $171-175$.

Ganther HE (1999) Selenium metabolism, selenoproteins and mechanisms of cancer prevention: complexities with thioredoxin reductase [review]. Carcinogenesis 20, 1657-1666.

Gill HS \& Cross ML (2000) Anticancer properties of bovine milk. British Journal of Nutrition 84(Suppl 1), 161-166.

Gray T, Koo J \& Nettesheim P (2001) Regulation of mucous differentiation and mucin gene expression in the tracheobronchial epithelium. Toxicology 160, 35-46.

Greenwald P, Clifford CK \& Milner JA (2001) Diet and cancer prevention. European Journal of Cancer 37, 948-965.

Guarente L \& Kenyon C (2000) Genetic pathways that regulate ageing in model organisms. Nature 408, 255-262.

Guidance for Industry (1999) Significant Scientific Agreement in the Review of Health Claims for Conventional Foods and Dietary Supplements. Fed Reg 64 245, 71794.

Habuchi T, Suzuki T, Sasaki R, Wang L, Sato K, Satoh S, Akao T, Tsuchiya N, Shimoda N, Wada Y, Koizumi A, Chihara J, Ogawa O \& Kato T (2000) Association of vitamin D receptor gene polymorphism with prostate cancer and benign prostatic hyperplasia in a Japanese population. Cancer Research 60 , 305-308.

Ingles SA, Garcia DG, Wang W, Nieters A, Henderson BE, Kolonel LN, Haile RW \& Coetzee GA (2000) Vitamin D receptor genotype and breast cancer in Latinas (United States). Cancer Causes Control 11, 25-30.

Ip C, Thompson HJ \& Ganther HE (2000) Selenium modulation of cell proliferation and cell cycle biomarkers in normal and premalignant cells of the rat mammary gland. Cancer Epidemiology Biomarkers and Prevention 9, 49-54.

Jiang C, Jiang W, Ip C, Ganther H \& Lu J (1999) Seleniuminduced inhibition of angiogenesis in mammary cancer at chemopreventive levels of intake. Molecular Carcinogenesis 26, 213-225.

Kensler TW, Curphey TJ, Maxiutenko Y \& Roebuck BD (2000) Chemoprotection by organosulfur inducers of phase 2 enzymes: dithiolethiones and dithiins. Drug Metabolism and Drug Interactions 17, 3-22.
Kim YI, Pogribny IP, Basnakian AG, Miller JW, Selhub J, James SJ \& Mason JB (1997) Folate deficiency in rats induces DNA strand breaks and hypomethylation within the p53 tumor suppressor gene. American Journal of Clinical Nutrition 65 , 46-52.

Knowles LM \& Milner JA (2000) Allyl sulfides modify cell growth. Drug Metabolism Drug Interactions 17, 81-107.

Kritchevsky D (1999) Caloric restriction and experimental carcinogenesis. Toxicological Sciences 52(2 Suppl), 13-16.

Kruse HP, Kleessen B \& Blaut M (1999) Effects of inulin on faecal bifidobacteria in human subjects. British Journal of Nutrition Nov 82, 375-382.

Lipkin M, Reddy B, Newmark H \& Lamprecht SA (1999) Dietary factors in human colorectal cancer. Annual Review of Nutrition 19, 545-586.

Liu JZ \& Milner JA (1992) Age, dietary selenium and quantity of 7,12- dimethylbenz(a)anthracene influence the in vivo occurrence of rat mammary DNA adducts. Journal of Nutrition 122, 1361-1368.

Ma J, Stampfer MJ, Giovannucci E, Artigas C, Hunter DJ, Fuchs C, Willett WC, Selhub J, Hennekens CH \& Rozen R (1997) Methylenetetrahydrofolate reductase polymorphism, dietary interactions, and risk of colorectal cancer. Cancer Research 57, 1098-1102.

Martinez ME \& Giovannucci E (1997) Diet and the prevention of cancer. Cancer Metastasis Review 16, 357-376.

Mason JB \& Levesque T (1996) Folate: effects on carcinogenesis and the potential for cancer chemoprevention. Oncology 10, $1727-1744$.

Milner JA (2000a) Nonnutritive components in foods as modifiers of the cancer process. In Preventive Nutrition, pp. 135-152. Totowa, NJ: The Humana Press.

Milner JA (2000b) Functional foods: the US perspective. American Journal of Clinical Nutrition 71(6 Suppl), $1654 \mathrm{~S}-1659 \mathrm{~S}$.

Nakamura Y, Tomokane I, Mori T, Tanaka A, Koutani J, Matsuo T, Okamoto S, Sato K \& Ohtsuki K (2000) DNA repair effect of traditional sweet pepper Fushimi-togarashi: seen in suppression of UV-induced cyclobutane pyrimidine dimer in human fibroblast. Bioscience Biotechnology Biochemistry 64, 2575-2580.

Paabo S (2001) Genomics and society. The human genome and our view of ourselves. Science 291, 1219-1220.

Pierre F, Perrin P, Champ M, Bornet F, Meflah K \& Menanteau J (1997) Short-chain fructo-oligosaccharides reduce the occurrence of colon tumors and develop gut-associated lymphoid tissue in Min mice. Cancer Research 57, 225-228.

Pinto MC, Garcia-Barrado JA \& Macias P (1999) Resveratrol is a potent inhibitor of the dioxygenase activity of lipoxygenase. Journal of Agriculture and Food Chemistry 47, 4842-4846.

Piyathilake CJ, Macaluso M, Johanning GL, Whiteside M, Heimburger DC \& Giuliano A (2000) Methylenetetrahydrofolate reductase (MTHFR) polymorphism increases the risk of cervical intraepithelial neoplasia. Anticancer Research 20(3A), 1751-1757.

Potter JD (1997) Cancer prevention: epidemiology and experiment. Cancer Letters 114, 7-9.

Ramos-Gomez M, Kwak MK, Dolan PM, Itoh K, Yamamoto M, Talalay P \& Kensler TW (2001) From the cover: sensitivity to carcinogenesis is increased and chemoprotective efficacy of enzyme inducers is lost in nrf2 transcription factor-deficient mice. Proceedings of the National Academy of Sciences USA 98, 3410-3415.

Rampersaud GC, Kauwell GP, Hutson AD, Cerda JJ \& Bailey LB (2000) Genomic DNA methylation decreases in response to moderate folate depletion in elderly women. American Journal of Clinical Nutrition 72, 998-1003. 
Rao CV, Chou D, Simi B, Ku H \& Reddy BS (1998) Prevention of colonic aberrant crypt foci and modulation of large bowel microbial activity by dietary coffee fiber, inulin and pectin. Carcinogenesis 19, 1815-1819.

Ratnasinghe D, Tangrea JA, Andersen MR, Barrett MJ, Virtamo J, Taylor PR \& Albanes D (2000) Glutathione peroxidase codon 198 polymorphism variant increases lung cancer risk. Cancer Research 60, 6381-6383.

Reddy BS (1999) Possible mechanisms by which pro- and prebiotics influence colon carcinogenesis and tumor growth. Journal of Nutrition 129(7 Suppl), 1478S-1482S.

Reddy BS, Hamid R \& Rao CV (1997) Effect of dietary oligofructose and inulin on colonic preneoplastic aberrant crypt foci inhibition. Carcinogenesis 18, 1371-1374.

Redman C, Scott JA, Baines AT, Basye JL, Clark LC, Calley C, Roe D, Payne CM \& Nelson MA (1998) Inhibitory effect of selenomethionine on the growth of three selected human tumor cell lines. Cancer Letters 125, 103-110.

Roberfroid M (1993) Dietary fiber, inulin, and oligofructose: a review comparing their physiological effects. Critical Reviews in Food Science and Nutrition 33, 103-148.

Rose DP \& Connolly JM (2000) Regulation of tumor angiogenesis by dietary fatty acids and eicosanoids. Nutrition and Cancer 37, 119-127.

Sakai T (2000) Biomarkers of lead exposure. Industrial Health 38, 127-142.

Schatzkin A, Lanza E, Corle D, Lance P, Iber F, Caan B, Shike M, Weissfeld J, Burt R, Cooper MR, Kikendall JW \& Cahill J (2000) Lack of effect of a low-fat, high-fiber diet on the recurrence of colorectal adenomas. Polyp Prevention Trial Study Group. New England Journal of Medicine $\mathbf{3 4 2}$, 1149-1155.

Schrauzer GN (2000) Anticarcinogenic effects of selenium. Cellular and Molecular Life Sciences 57, 1864-1867.

Sinha R, Said TK \& Medina D (1996) Organic and inorganic selenium compounds inhibit mouse mammary cell growth in vitro by different cellular pathways. Cancer Letters 107, $277-284$

Skibola CF, Smith MT, Kane E, Roman E, Rollinson S, Cartwright RA \& Morgan G (1999) Polymorphisms in the methylenetetrahydrofolate reductase gene are associated with susceptibility to acute leukemia in adults. Proceedings of the National Academy of Sciences USA 96, 12810-12815.

Slattery ML, Potter JD, Samowitz W, Schaffer D \& Leppert M (1999) Methylenetetrahydrofolate reductase, diet, and risk of colon cancer. Cancer Epidemiology Biomarkers and Prevention 8, 513-518.

Smith-Warner SA, Spiegelman D, Yaun SS, Adami HO, Beeson WL, van den Brandt PA, Folsom AR, Fraser GE, Freudenheim JL, Goldbohm RA, Graham S, Miller AB, Potter JD, Rohan TE, Speizer FE, Toniolo P, Willett WC, Wolk A, Zeleniuch-Jacquotte A \& Hunter DJ (2001) Intake of fruits and vegetables and risk of breast cancer: a pooled analysis of cohort studies. Journal of the American Medical Association 285, 769-776.

Subbaramaiah K, Michaluart P, Chung WJ, Tanabe T, Telang N \& Dannenberg AJ (1999) Resveratrol inhibits cyclooxygenase- 2 transcription in human mammary epithelial cells. Annals New York Academy of Sciences 889, 214-223.

Suk WA \& Collman GW (1988) Genes and the environment: their impact on children's health. Environmental Health Perspective 106, 817-820.

Taper HS \& Roberfroid M (1999) Influence of inulin and oligofructose on breast cancer and tumor growth. Journal of Nutrition 129(7 Suppl), 1488S-1491S.

Van Duyn MA \& Pivonka E (2000) Overview of the health benefits of fruit and vegetable consumption for the dietetics professional: selected literature. Journal of the American Dietetic Association 100, 1511-1521.

Vineis P, Malats N, Lang M, d'Errico A, Caporaso N, Cuzick J \& Boffetta P (editors) (1999) Metabolic Polymorphisms and Susceptibility to Cancer, pp. 1-510. Lyon, France: International Agency for Research on Cancer.

Ward WE, Jiang FO \& Thompson LU (2000) Exposure to flaxseed or purified lignan during lactation influences rat mammary gland structures. Nutrition and Cancer 37, $187-192$

Wargovich MJ (1999) Nutrition and cancer: the herbal revolution. Current Opinion in Clinical Nutrition Metabolic Care 2, 421-424.

Weisburger JH (2000) Prevention of cancer and other chronic diseases worldwide based on sound mechanisms. Biofactors 12, 73-81.

Whiteley LO \& Klurfeld DM (2000) Are dietary fiber-induced alterations in colonic epithelial cell proliferation predictive of fiber's effect on colon cancer? Nutrition and Cancer 36, $131-149$.

Woodson K, Ratnasinghe D, Bhat NK, Stewart C, Tangrea JA, Hartman TJ, Stolzenberg-Solomon R, Virtamo J, Taylor PR \& Albanes D (1999) Prevalence of disease-related DNA polymorphisms among participants in a large cancer prevention trial. European Journal of Cancer Prev 8, 441-447.

Wynder EL \& Gori GB (1977) Contribution of the environment to cancer incidence: an epidemiologic exercise. Journal of the National Cancer Institute 58, 825-832.

Zhou JR, Gugger ET, Tanaka T, Guo Y, Blackburn GL \& Clinton SK (1999) Soybean phytochemicals inhibit the growth of transplantable human prostate carcinoma and tumor angiogenesis in mice. Journal of Nutrition 129, 1628-1635.

Zhu K \& Williams SM (1998) Methyl-deficient diets, methylated ER genes and breast cancer: an hypothesized association. Cancer Causes Control 9, 615-620.

Zhu Z, Jiang W, Ganther HE, Ip C \& Thompson HJ (2000) In vitro effects of Se-allylselenocysteine and Se-propylselenocysteine on cell growth, DNA integrity, and apoptosis. Biochemical Pharmacology 60, 1467-1473. 